\title{
PART-LOAD OPTIMA IN BOTTOMING-CYCLES
}

\author{
JOHN B. WOODWARD \\ Naval Architecture and Marine Engineering, University of Michigan, Ann Arbor, MI 48109, U.S.A \\ (Received 14 November 1986)

\begin{abstract}
It is assumed that optimal steam conditions for a Rankine bottoming-cycle are those that produce the greatest power output. It is then demonstrated that optimal steam conditions are a function of steam-generator pinch-temperature difference, leading to the assumption that a designer of bottoming-cycles may begin with a chosen pinch-temperature difference. Further demonstration is given that the pinch-temperature difference must change in response to primary engine load changes, so that such load changes upset the optimal bottoming-cycle conditions found at primary engine-rated power. The consequences to the bottoming-cycle in terms of lost power capability are demonstrated and are found to be of small magnitude.
\end{abstract}

\section{NOMENCLATURE}

$A_{1}, A_{2}$ heat transfer area of evaporator and preheater, respectively

$\Delta A \quad$ preheater area over which boiling occurs at low load

$C$ numerical coefficient, $\mathrm{kW} / \mathrm{kJ} \mathrm{hr}$

$c_{\theta p} \quad$ constant pressure specific heat of primary engine exhaust gas

$D$ diameter

e base of natural logarithms

$e_{b}, e_{l}, e_{t}$ basic efficiency, load correction, temperature correction of turbine generator, respectively enthalpy

heat exchanger film coefficient

conductivity

load

primary engine exhaust gas mass-flow rate

bottoming-cycle steam mass-flow rate

Prandtl number

steam pressure

Reynolds number

entropy

temperature

$T_{1}, T_{2}$ exhaust gas temperature at beginning, end of waste heat exchangers

$\Delta T_{p} \quad$ pinch-temperature difference

$U_{1}, U_{2}$ overall heat transfer coefficient of evaporator, preheater, respectively

$w$ power, output of bottoming-cycle

\section{Subscripts on $h, T$}

$f \quad$ saturated liquid at evaporating temperature

$f f$ saturated liquid at surroundings and feedwater temperature

fg change during evaporation

$g \quad$ saturated vapor

s "of steam", either dry saturated or superheated

\section{INTRODUCTION}

This paper is concerned with optimizing the Rankine bottoming-cycle that may be used with a primary gas turbine engine, with optimization implying choice of steam conditions that lead to the maximum net output of bottoming-cycle power. Optimization often has a much broader scope, particularly in marine applications, where the consequences to weight and volume of machinery are certain to be included in the overall measure of merit. However, the points investigated can be illuminated by considering only maximization of the output of the bottoming-cycle through choice of steam pressure and temperature.

The optimization is a simple process that can be accomplished with steam tables and a 
pocket calculator. It surely has been done many times by many designers and investigators to the point where its discussion has become trivial. Here, though, we look at an added dimension of the optimization question, namely, how optimal conditions may change when a major change of primary engine load takes place. if, say, a bottoming-cycle is optimized for $100 \%$ primary engine load, will a change in primary load to $50 \%$ result in steam conditions that are optimal for the new bottoming-cycle load? If not, are the consequences significant enough to command attention in the original optimization process?

The key parameter in establishing steam conditions is the pinch-temperature difference encountered in preheating, evaporating, and superheating steam, i.e. the smallest difference in temperature between the gas turbine exhaust and the saturation temperature of the steam. The value of this parameter largely determines the amount of energy transferred and the size of the heat transfer surfaces; the smaller this difference, the greater the amount of energy extracted from engine exhaust, and the greater the size of the necessary heatexchange surface.

It is assumed that a designer, working at the rated point of the primary engine, chooses a reasonable value of pinch-temperature difference and then proceeds to find optimal steam conditions with this difference fixed. As a corollary, the necessary heat-transfer area is found. When the primary load changes, the pinch-temperature difference must vary to suit the unchanging surface area and the circumstances of the load change. It is to be demonstrated that this change in pinch-temperature difference does occur, and that the optimal stcam conditions are a function of this difference. A change in primary load therefore must shift bottoming-cycle steam conditions away from the designer's optimum. Predictions are made of the magnitudes of possible changes of this nature, and observations are made as to the significance of the changes.

Optimal steam conditions for a bottoming-cycle are nominally those which produce the largest product of steam availability and steam mass-flow rate. However, steam-turbine efficiency is a function of the pressure and temperature at which it operates and may modify the dictates of that product. This factor is also treated. The effects to be demonstrated are shown, in part, by means of numerical work. For this purpose, exhaust flows and temperatures for the General Electric LM2500 gas-turbine engine are used.

\section{EARLIER WORK}

Attention in preparation of this paper has been concentrated on the RACER (an acronym) bottoming-cycle being developed for marine use by the U.S. Navy and Solar Turbines Incorporated. This development has been widely reported in the engineering literature. ${ }^{1-2}$ However, none of the literature reveals any consideration of primary load-change effects on optimization, and the more general literature of bottoming-cycles shows the same deficiency.

Consideration of cogeneration should also be included in a literature review because of the close kinship of cogeneration to the bottoming-cycle concept. Here one finds that some authors have incorporated load changes in their work. ${ }^{4.5}$ However, the authors of these papers do not discuss the question of how optimization may be affected by load changes.

\section{MAXIMAL BOTTOMING-CYCLE OUTPUT AS FUNCTION OF PINCH- TEMPERATURE DIFFERENCE}

Optimal steam conditions are to be chosen for the Rankine bottoming-cycle, with optimal implying the greatest possible gross output from the cycle. The net output includes deduction for feedpump work, a factor that we can afford to neglect because optimal steam pressures are low. From elementary considerations, the electrical gross output of the bottoming-cycle is the product of steam mass-flow rate, availability of the steam, and efficiency of the turbine, i.e.

$$
w=C m_{s}\left[\left(h_{s}-h_{f f}\right)-T_{f f}\left(s_{s}-s_{f f}\right)\right]\left[e_{b} e_{t} e_{l}\right]
$$


with

$$
\begin{gathered}
m_{s}=m_{g} c_{g p}\left(T_{1}-T_{2}\right) /\left(h_{s}-h_{f f}\right) \quad \text { (overall) } \\
m_{s}=m_{g} c_{g p}\left(T_{s}+\Delta T_{p}-T_{2}\right) /\left(h_{f}-h_{f f}\right) \quad \text { (in the preheater) }
\end{gathered}
$$

Equations (2) and (3) can be combined to give the steam flow in terms of the pinchtemperature difference $\Delta T_{p}$. This relationship may be substituted into Eq. (1) to give electrical gross output in terms of the chosen steam conditions and chosen pinchtemperature difference as follows:

$$
w=\left\{C\left[m_{g} c_{g p} e_{b} e_{t} e_{l}\right]\left[T_{1}-T_{s}-\Delta T_{p}\right]\left[\left(h_{s}-h_{f f}\right)-T_{f f}\left(s_{s}-s_{f f}\right)\right] /\left[h_{s}-h_{f}\right]\right\} .
$$

To find the maximum, Eq. (4) is differentiated and set equal to zero. However, if the task is to find optimal steam pressure, then relationships for $T_{s}, h_{s}, h_{f}, s_{s}$, and $e_{b}$ must be supplied. For the first four of these, linear approximations that are accurate on the saturation line in the neighborhood of $3.5 \mathrm{MPa}$ pressure are used. The relation for $e_{b}$, the turbine basic efficiency, is a function of pressure only and is linear over a wide range of pressures. The data for this factor, as well as for $e_{t}$ and $e_{l}$, are from Ref. 6 . The steam pressure becomes the independent variable, the pinch-temperature difference remains as the parameter of interest, and other quantities are treated as constants.

Since the steam properties are to be treated as functions of pressure only, the following development applies only to saturated steam. This limitation is imposed because the results are affected only slightly by the inclusion of variable amounts of superheat. The validity of this assertion will be demonstrated. The five relationships to be combined with Eq. (4) are

$$
\begin{gathered}
T_{s}=184.9+16.5 P_{s}, \\
h_{s}=2813-2.8 P_{s}, \\
h_{f g}=2040-81.7 P_{s} \text { (used in lieu of } h_{s}-h_{f} \text { when steam is saturated), } \\
s_{s}=6.5341-0.1168 P_{s}, \\
e_{b}=0.6788-0.009135 P_{s},
\end{gathered}
$$

When these are substituted into Eq. (4) it becomes

$$
\begin{aligned}
w=\left\{C\left[0.6788-0.009135 P_{s}\right]\right. & {\left[T_{1}-\Delta T_{p}-184.9-16.5 P_{s}\right]\left[2813-2.8 P_{S}-h_{f f}\right.} \\
& \left.\left.-T_{f f}\left(6.5341-0.1168 P_{s}-s_{f f}\right)\right] /\left[2040-81.7 P_{s}\right]\right\}
\end{aligned}
$$

To demonstrate the effect of steam pressure and pinch-temperature difference on maximum electrical power production, the derivative of Eq. (10) with respect to pressure can be set equal to zero. If values for the constants appropriate for a pressure of $3.5 \mathrm{MPa}$ are used, the process produces

$$
\begin{aligned}
& 0=\left[2040-81.7 P_{s}\right]\left[-10960-8.484 \Delta T_{p}\right.\left.+\left(297.4-0.02558 \Delta T_{p}\right) P_{s}-1.266 P_{s}{ }^{2}\right] \\
&+81.7 P_{s}\left[1.6641-489.2 \Delta T_{p}-\left(10960+8.484 \Delta T_{p}\right) P_{s}\right. \\
&\left.+\left(148.7-0.01279 \Delta T_{p}\right) P_{s}{ }^{2}-0.422 P_{s}{ }^{3}\right]
\end{aligned}
$$

That the optimal value of steam pressure depends on the choice of pinch-temperature difference is evident from inspection of Eq. (11). However, the form and degree of the 
dependence is difficult to see. The best expedient is to plot Eq. (10) for a range of pressures and for a range of pinch-temperature differences, Fig. 1. In constructing Fig. 1, corrections were made for the inaccuracies of Eqs. (5-8) at pressures distant from $3.5 \mathrm{MPa}$.

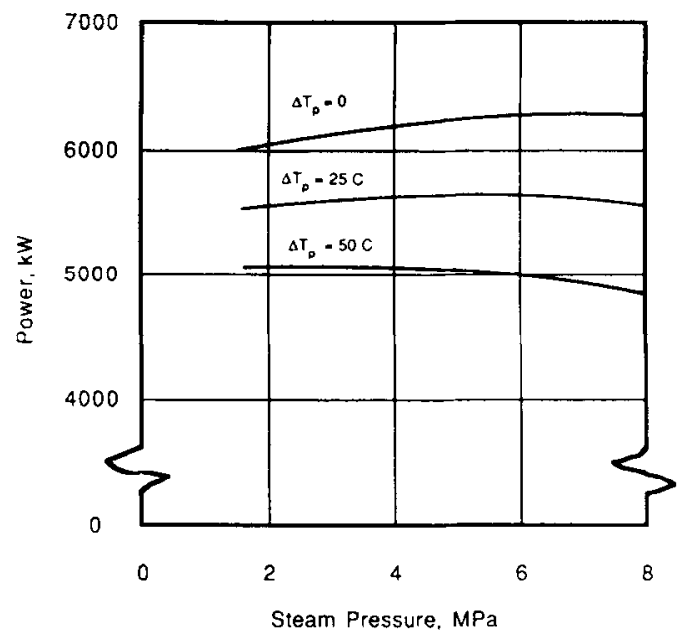

Fig. 1. Electrical power output of Rankine bottoming-cycle as a function of cycle pressure (saturated steam) with pinch-temperature difference as a parameter.

The dependency of the bottoming-cycle output on choice of pinch-temperature difference is quite evident in Fig. 1; the dependence of optimal pressure on the choice is not so clear because of the flatness of the curves. A crossplot, Fig. 2, constructed with the aid of Eq. (11), shows more clearly the relationship between the pressure for greatest output and choice of pinch-temperature difference.

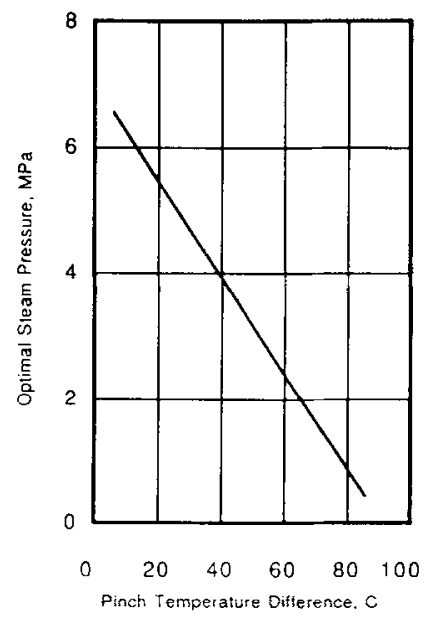

Fig. 2. Crossplot of Fig. 1, showing optimal steam pressure as a function of pinch-temperature difference.

\section{THE CHANGE IN PINCH-TEMPERATURE DIFFERENCE WHEN LOAD CHANGES}

When the load carried by the primary engine changes, the energy it supplies to the bottoming-cycle must change in ways dictated by the primary engine characteristics. The heat transfer area that links the two cycles does not change (unless deliberately changed, an option that is explored later). The pinch-temperature difference is established at the value dictated by the unchanging area and by changes in system parameters.

The new pinch-temperature difference can be found by simultaneous solution of the 
energy balance and heat transfer equations using, for example, Eqs. (12-15). The following conditions apply: (1) dry saturated steam is produced; (2) boiling is allowed in the preheater; so that effectively an area $\Delta A$ is transferred from preheating to boiling functions. We find

$$
\begin{gathered}
m_{g} c_{g p}\left(T_{1}-T_{s}-\Delta T_{p}\right)=U_{1}\left(A_{1}+\Delta A\right)\left(T_{1}-T_{s}-\Delta T_{p}\right) / \log _{e}\left[\left(T_{1}-T_{s}\right) / \Delta T_{p}\right] \\
m_{g} c_{g p}\left(T_{1}-T_{s}-\Delta T_{p}\right)=m_{s}\left(h_{s}-h_{t}\right) \\
m_{s}\left(h_{f}-h_{f f}\right)=m_{g} c_{g p}\left(T_{s}+\Delta T_{p}-T_{2}\right) \\
m_{g} c_{g p}\left(T_{s}+\Delta T_{p}-T_{2}\right)=U_{2}\left(A_{2}-\Delta A\right)\left(T_{2}-T_{f f}-\Delta T_{p}\right) / \log _{e}\left[\left(T_{2}-T_{f f}\right) / \Delta T_{p}\right]
\end{gathered}
$$

These equations can be combined to produce an implicit equation for the pinch-temperature difference in terms of the primary engine exhaust-gas flow rate, gas specific heat, gas temperature, heat exchanger parameters, and steam states, viz.

$$
\begin{aligned}
& m_{g} c_{g p} H_{1}\left[T_{1}-T_{s}-\Delta T_{p}\right] \log _{e}\left\{\left[H_{2}\left(T_{s}+\Delta T_{p}\right)-H_{1} T_{1}-T_{f f}\right] / \Delta T_{p\}}\right\}=\left(U_{2} / U_{1}\right) \\
& \times\left\{U_{1} A_{2}-m_{g} c_{g p} \log _{e}\left[\left(T_{1}-T_{s}\right) / \Delta T_{p}\right]+U_{1} A_{1}\right\}\left[H_{2}\left(T_{s}+\Delta T_{p}\right)-H_{1} T_{1}-T_{f f}-\Delta T_{p}\right] .
\end{aligned}
$$

where $H_{1}=\left(h_{f}-h_{f f}\right) /\left(h_{s}-h_{f}\right)$ and $H_{2}=1+H_{1}$ Figure 3 produced from Eq. (16) with typical numerical values is a plot of pinch-temperature difference as a function of primary load. It demonstrates the decrease in pinch-temperature difference that occurs when primary load decreases.

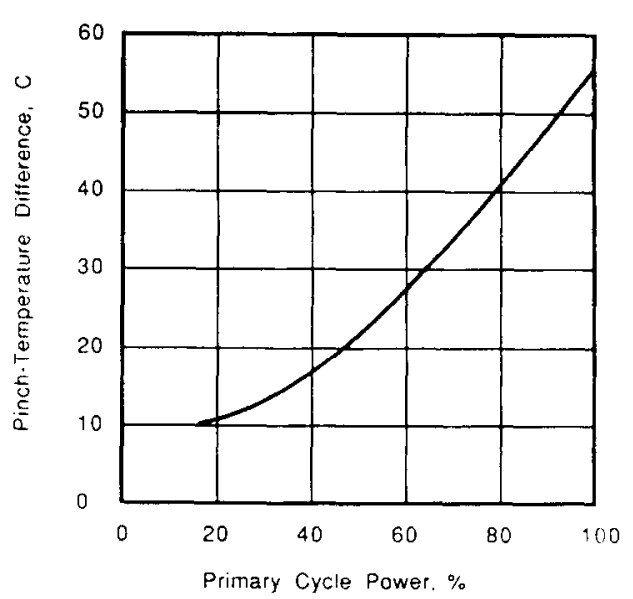

Fig. 3. Typical variation of pinch-temperature difference as a function of primary cycle load.

\section{CONSEQUENCES OF A CHANGED PINCH-TEMPERATURE DIFFERENCE}

Figure 4 demonstrates the results that are developed in the preceding section, namely that optimal steam pressure for a bottoming-cycle is a function of a chosen pinchtemperature difference, and that a change in primary load produces a change in the pinchtemperature difference. Except in fortuitous circumstances, the optimal pressure thus changes when load changes. The curves of Fig. 4 are plots of Eq. (4) with pinch-temperature differences of 50 and $20 C$ for full and half loads, respectively.

Because the flatness of the curves makes reading of the high points difficult to detect at small scale, these points are marked, and are seen to occur at different pressures.

Pcrhaps the most significant point to be made from Fig. 4 is the flatness of the curves. Although keeping pressure constant as the primary load declines does shift the operating point away from the its optimum, the consequent loss in output at half load is only $0.8 \%$. 


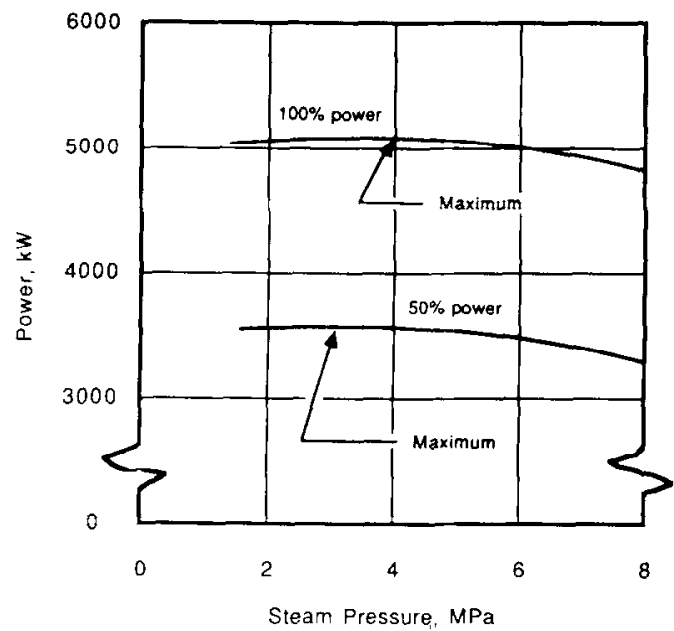

Fig. 4. Bottoming-cycle electric power at $100 \%$ and $50 \%$ primary cycle load.

The results may be of greater magnitude under different circumstances, for example, if steps were taken to prevent boiling in the preheater at low loads. Several such alternatives are examined in following sections.

\section{NO BOILING IN THE PREHEATER}

Boiling in the preheater under low loads can be prevented by several expedients such as bypassing some of the primary engine exhaust gas, or by closing off part of the preheater tube bank. The effect on Eqs. $(12-15)$ is to eliminate $\Delta A$ from these equations, a step that uncouples Eqs. (12) and (13) from the remaining two. From Eqs. (12) and (13) the pinchtemperature difference is readily found to be

$$
\Delta T_{p}=\left(T_{1}-T_{s}\right) \mathrm{e}^{-U_{1} A_{1} / m_{\mathbf{g}} c_{g p}}
$$

With this, the equation for bottoming-cycle power output, equivalent to Eq. (4) is

$$
w=\left\{C\left[m_{g} c_{g p} e_{b} e_{t} e_{l}\right]\left[T_{1}-T_{s}\right]\left[1-\mathrm{e}^{-U_{1} A_{1} / m_{g} f_{g p}}\right]\left[\left(h_{s}-h_{f f}\right)-T_{f f}\left(s_{s}-s_{f f}\right)\right] /\left[h_{s}-h_{f}\right]\right\} .
$$

Figure 5 shows the consequences of preventing preheater boiling. This figure is Fig. 4 with an added line to show bottoming-cycle output predicted by Eq. (18). The output is lower, as expected, but the part-load shift of optimal pressure is imperceptible.

\section{EFFECT OF A CHANGE IN THE OVERALL HEAT-TRANSFER COEFFICIENT}

To this point the overall heat transfer coefficients of evaporator and preheater have been treated as constants in the face of primary load changes. The validity of this restriction is now examined.

The heat exchangers are likely to consist of finned tubes in cross flow. Overall heat transfer coefficients of approximately $160 \mathrm{~kJ} / \mathrm{m}^{2} \mathrm{hr} C$ appear to be typical. ${ }^{7,8}$ This value appears to be roughly equal to an estimated value for a film coefficient on the gas side (outside) of the tubes, so that this discussion can be based on the gas-side coefficient. For that coefficient, we use the relation

$$
h=f(k / D), \operatorname{Re}^{0.6}, \operatorname{Pr}^{0.3}
$$




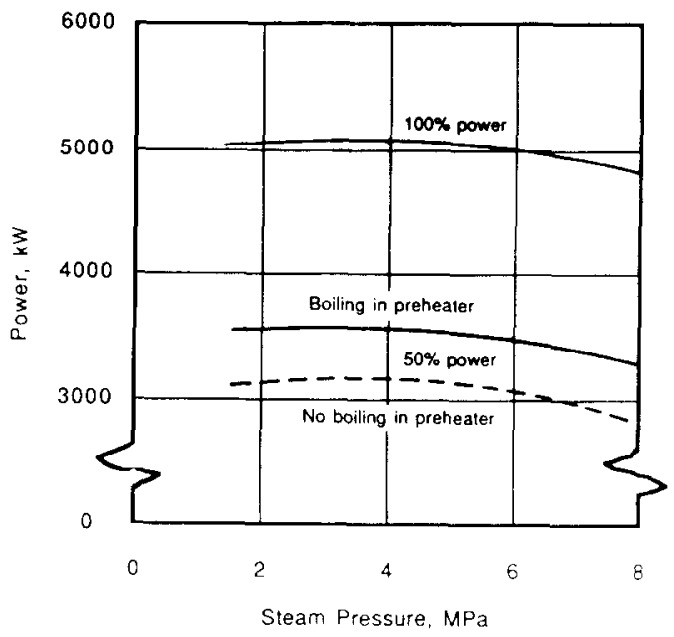

Fig. 5. A repeat of Fig. 4 with the addition of a curve to show bottoming-cycle output when boiling in the preheater at low loads is not allowed.

The derivative of film coefficient with respect to load (and hence of overall coefficient with respect to load) can be found via chain-rule differentiation, starting with

$$
\mathrm{d} h / \mathrm{d} L=f(\sigma k / \sigma L, \sigma \operatorname{Re} / \sigma L, \sigma \operatorname{Pr} / \sigma L)
$$

With numerical values appropriate to the middle of the pressure range investigated above, Eq. (20) produces a sensitivity $(1 / h(\mathrm{~d} h / \mathrm{d} L))=0.15$ which, as stated, is also to express the change in overall heat transfer coefficient. When primary engine load declines by $50 \%$, overall heat transfer coefficient is therefore estimated to decline by $7.5 \%$.

And the consequence? The decline in overall coefficient just mentioned requires the pinch-temperature difference to rise about $15 \%$ above the value it would otherwise have at $50 \%$ primary engine load. The maximum bottoming-cycle output decreases by about $2 \%$. The optimal pressure is slightly lower than otherwise, but the flatness of the bottoming output vs steam pressure is still evident, so that the consequences of the shift in optimum are still of no great consequence.

\section{THE EFFECT OF SUPERHEAT}

Superheat is to be expected in a Rankine bottoming-cycle. Figure 6 illustrates a major benefit, namely, a higher output from the same input from the primary cycle, and the same pinch temperature difference. As an example, the figure shows the increased output provided by $100 C$ superheat.

The figure also shows the reduced output at $50 \%$ primary cycle load. The pinchtemperature difference is 25 instead of $45 \mathrm{C}$, and supcrheat is about $125 \mathrm{C}$. As with the simpler saturated steam case discussed earlier, the pressure for maximum bottoming-cycle output shifts to a lower pressure, but the flatness of the output vs pressure curve robs this phenomenon of significance.

\section{CONCLUSIONS}

It is demonstrated by means of Eq. (11) and supporting numerical work that the optimal (highest output) steam conditions for a Rankine bottoming-cycle are a function of the pinch-temperature difference chosen for the heat-transfer equipment. Using Eq. (16) and supporting numerical work, it is found that the pinch-temperature difference changes when the primary engine load changes. These two occurrences taken together point to the conclusion that the bottoming-cycle will lose its optimality as a consequence of primary 


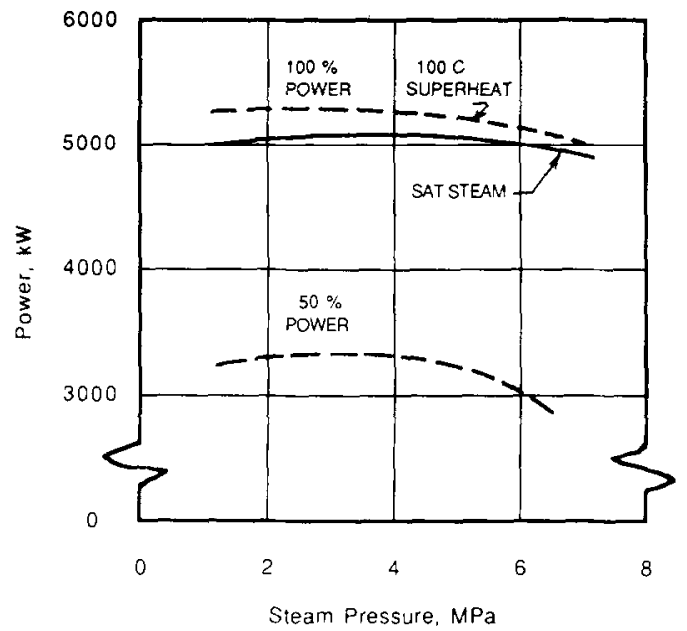

Fig. 6. A repeat of Fig. 4 with the addition of a curve to show bottoming-cycle output with $100 \mathrm{C}$ superheat when the primary cycle is at $100 \%$ load.

load change. However, the numerical work shows that in all cases studied, the loss in gross bottoming-cyclc output as a consequence of the optimality shift is so small that analysts of bottoming cycles are justified in treating it as negligible.

\section{REFERENCES}

1. C. L. Miller and H. D. Marron, RACER-An Energy Conserving System for Ship Propulsion, Proc. 16th IECEC, Atlanta, Ga (1981).

2. W. S. Mattson, Nav. Engnrs, 94, 63 (1982).

3. J. T. Halkola, A. H. Campbell, and D. Jung, RACER Conceptual Design. American Society of Mechanical Engineers paper 83-GT-50, Phoenix, Ariz. (1983)

4. J. W. Baughn, A. A. McKillop, and K. Treleven, J. Engng Power 105, 816 (1983).

5. K. Treleven, J. W. Baughn, and A. A. McKillop, Energy 8, 547 (1983).

6. Technical and Research Bulletin 3-27, Marine Diesel Power Plant Performance Practices. Society of Naval Architects and Marine Engineers, New York, N.Y. (1975).

7. D. R. Logeais, Design of a Heat Recovery Steam Generator, American Society of Mechanical Engineers paper 84-GT-160, New York, N.Y. (1984).

8. V. L. Eriksen, N. M. Froemming, and M. R. Carroll, Design of Gas Turbine Exhaust Heat Recovery Boiler Systems, American Society of Mechanical Engineers paper 84-GT-126, New York, N.Y. (1984).

9. F. Kreith, Principles of IIeat Transfer, 2 nd edn. p. 421. International Textbook Company, Scranton, Penn. (1965). 